\title{
HOMBRE EN CAMINO DE NATSUME SOOSEKI: UNA «VERSIÓN» JAPONESA DE EL CURIOSO IMPERTINENTE DE CERVANTES *
}

«Enseña el Cristo: a tu prójimo / amarás como a ti mismo, / mas nunca olvides que es otro. / Dijo otra verdad: / busca el tú que nunca es tuyo, / ni puede serlo jamás»

(Antonio Machado)

«No puedo definirte sino amándote»

(Leopoldo Panero)

Natsume Sôseki (1867-1916) está considerado como el más importante novelista japonés de los últimos 120 años, desde que Japón, tras un aislamiento de dos siglos y medio, abriera en 1868 sus puertas definitivamente a Occidente ${ }^{1}$. El primer contacto de Sôseki con la gran novela de Cervantes tuvo lugar en Londres, donde residió algo más dos años (1900-1902) como estudiante becado por el gobierno de su país. Ya de regreso en Tokyo, impartió clases de literatura inglesa en la Universidad Imperial hasta que en 1907 abandonó la enseñanza para dedicarse de lleno a la creación literaria. Entre los libros de su biblioteca tenía dos traducciones inglesas del Quijote, una que probablemente nunca uś́ y otra, de Tobias Smollet, en la que aparecen algunos refranes por él subrayados ${ }^{2}$.

* El presente estudio contiene el texto de una ponencia presentada por el autor en el IV Coloquio Internacional de la Asociación de Cervantistas, el día 27 de noviembre de 1991, en la Universidad de Alcalá de Henares. Con la debida autorización de D. José M." Casasayas, en nombre de la Asociación de Cervantistas, viene hoy a las páginas de Anales Cervantinos, que se honran nuevamente con la valiosa colaboración de Jaime Fernández, S. J. LA Redacción.

1 Para una información general sobre Sôseki, véase BEONGCHEON Yu, Natsume Sóseki. New York, Twayne, 1969. También TAKeo Dor, The Psychological World of Natsume Sóseki. Translated by William J. Tyler. Cambridge, Massachusetts, Harvard University, East Asian Research Center, 1976.

2 Datos proporcionados por TAKehIKo KenMochI, *Tairiku Bungaku, Hispaniya Bungaku» [Literatura continental. Literatura Española]. En TAKEHIKo KENMOchI, ed., Soseki to Gaikoku Bungaku, Natsume Sóseki Hikkei II [Sôseki y la literatura extranjera -Datos indispensables para Natsume Sóseki II-]. Tokyo, Gakutôsha, 1982, pp. 184-186. 
Aunque Sôseki nunca reconoció en público la inmensa deuda que había contraído con el genio de Cervantes ${ }^{3}$, las huellas que el Quijote dejó en su obra, al menos en Hombre en camino (Kójin), son innegables ${ }^{4}$. Es más, puedo afirmar, sin margen de error, que Natsume Sôseki no sólo leyó el Quijote, sino también que, en particular, leyó y releyó muchas veces la novelita intercalada de $E l$ curioso impertinente, como podrá comprobar el lector que llegue al final de estas páginas. Y hago esta afirmación no ya por el título, Hombre en camino (o Caminante), de tan hondas resonancias con el de "andante» adoptado por el hidalgo manchego, sino principalmente por la escena en que Ichirô ruega a su hermano Jirô tiente

3 Sólo en dos ocasiones hizo Sôseki comentarios de carácter más bien general y anodino sobre el Quijote. Cierto que apreció la gran novela de Cervantes como un importante acervo literario de refranes, pero no pas 6 de considerarla como una obra cómica. Sobre este punto, véase el artículo antes citado de Takehiko Kenmochi; también Seroban Taro, «Nihon Kindai Bungaku to Don Kihôte» [Don Quijote y la literatura japonesa moderna] (Apéndice). En Don Kihóte Noto [Notas a «Don Quijote»], núm. 4 Kagoshima (Edic. del autor), 1987, marzo, pp. 46-49; igualmente TADASHI OSHIMA, «Don Kihôte zakkan» [Impresiones varias sobre Don Quijote], en Supein Bungaku e no Sasoi [Invitación a la literatura espanoola]. Tokyo, Sóseikisha, 1978, pp. 215-216. Por otra parte, KII NAKANo en su artículo «Kyôki no Hohôka: Kôjin to Don Kihôte» [Metodización de la locura: Hombre en camino y Don Quijote], en English Literature and Language ["Eigogaku to eibungaku"]. Tokyo, Sophia University, Dept. of English Literature, 1983, núm. 9, pp. 91-99, se lamenta de que Sôseki nunca se refiriera a la fuente de su novela, ya que con ello privó a la crítica posterior de un instrumento necesario para establecer su estructura. La razón de su silencio estriba, a mi parecer, en que el gran novelista japonés nunca se llegó a percatar del valor del Quijote, aparte de que su mención pudo considerarla innecesaria o contraproducente a causa de la ignorancia que en el Japón de entonces había respecto a la cultura espanola. Prefirió citar a Meredith, Mallarmé, el episodio de Paolo y Francesca, etc.

4 Para el presente estudio he usado el texto original japonés de la Editorial Shinchôsha (Colección «Shinchô», núm. 308. Tokyo, 1989 (72." reimpresión). Igualmente he consultado la traducción inglesa de BEONGCHEON YU, The Wayfarer. Tokyo, Charles E. Tuttle Co., Publishers, 1967, precedida de una amplia introducción. En ella se senala de pasada la semejanza temática - metafísica - entre El curioso y Hombre en camino (p. 23).

Para las citas de la novela de Sóseki uso esta traducción del Prof. Yu, indicando con número romano cada una de las cuatro partes de la novela (I, «Mi amigo». II, «Mi hermano». III, «De vuelta en Tokyo». IV, «Angustia») y con número arábigo cada uno de sus capítulos. Éstos son relativamente breves, ya que Sôseki fue publicando su novela por entregas en el periódico Asahi de Tokyo.

Entre los autores japoneses que han apuntado la semejanza, citamos a TAKEO Dor (obra cit.), quien alude a ello muy brevemente ignorando si Sôseki se inspiró en la novela de Cervantes. Nakano KII (art. cit.) trata el tema con más amplitud, aunque en tonos muy generales. Finalmente, Yoshinori NishinaGa, escribe un amplio estudio comparativo («Mohó to bungaku. Natsume Sôseki Kojin wo megutte» [Literatura e imitación. En torno a Hombre en camino de Natsume Sóseki]. Sekai, 1980, pp. 289-304), centrado en la metafísica del deseo de René Girard. 
a Nao, su propia esposa. Tal escena es por sí misma prueba suficiente, pues carece en absoluto de precedentes en la historia de la literatura japonesa ${ }^{5}$.

Que las dos figuras centrales masculinas de Hombre en camino sean hermanos y no amigos obedece, ante todo, a una tendencia muy arraigada en la literatura japonesa de todos los tiempos, que en mucha mayor medida que la española, gusta de plantear conflictos en el seno familiar ${ }^{6}$. Pero además la posibilidad del vínculo "familiar" ya estaba insinuada por el mismo Cervantes en el segundo párrafo de su novela: «con todo esto, es tan delicada la honra del casado, que parece que se puede ofender aun de los mesmos hermanos, cuanto más de los amigos» $[33,398]^{7}$. Y es interesante comprobar cómo a lo largo de la novela de Sôseki la estancia de Jirô en el hogar familiar supone, en opinión de familiares y amigos, un constante semillero de problemas para las relaciones matrimoniales de Ichirô y Nao. Por otra parte, la comparación del vínculo - de amistad o de sangre- que une a los personajes masculinos de ambas novelas pone de relieve en $E l$ curioso un aspecto no suficientemente destacado por la crítica cervantina. Pues hace ver hasta qué punto Cervantes ha querido concentrarse en las figuras de ese triángulo humano - Anselmo, Lotario y Camila-, aislarlas de toda dimensión familiar (no existen en El curioso ni padres, ni hijos, ni hermanos) y hundirlas en un hermético infierno, asfixiante círculo vicioso, cuya salida comienza a hacerse posible sólo por la intervención fortuita de otras dos personas, Leonela y su amante, quienes no estando implicados originalmente en dicho triángulo absurdo, representan en cierto sentido la dimensión social.

Ciertamente la voz narradora en ambas novelas es distinta -tercera persona en Cervantes, primera persona (Jirô) en Sôseki-, con las lógicas consecuencias que de tal diferencia se desprenden. Pero las estructuras de El curioso y de Hombre en camino son básicamente idénticas, en cuanto que están marcadas o definidas por el momento axial de la escena en que Anselmo e Ichirô, piden

5 A diferencia de El curioso, cuyas abundantes fuentes en la literatura europea han sido rastreadas por JuAn B. Avalle-ARCe «El cuento de los dos amigos (Cervantes y la tradición literaria. Primera perspectiva)», en Nuevos deslindes cervantinos. Barcelona, Editorial Ariel, 1975, pp. 155-211.

- Dato que pude comprobar personalmente, respecto a los teatros clásicos más representativos de ambos paises, en mi tesis doctoral de literatura comparada: Filosofia del honor en el pueblo según los teatros de Lope de Vega y Monzaemon Chikamatsu (inedita). Madrid, Universidad Complutense, Facultad de Filosoffa y Ciencias de la Educación, 1984.

7 Para El curioso impertinente uso la edición del Quijote de Juan B. AvalleArce. Madrid, Editorial Alhambra, 1979. Cito entre conchetes, indicando capitulo y página. 
respectivamente a una tercera persona (amigo en Cervantes, y hermano en Sôseki) tienten a sus respectivas esposas, para poner a prueba la verdad de su honor. Son momentos llenos de intensidad semántica. La sorpresa del lector es quizá tan violenta como la que sienten Lotario y Jirô, receptores de la descabellada propuesta. Y, aunque el lector siga leyendo la narración hasta el fin, movido por la lógica curiosidad de saber el comportamiento subsiguiente de ese triángulo humano, se siente igualmente intrigado por las actitudes y relaciones mantenidas por esos mismos personajes hasta la escena crucial, y trata de buscar datos que psicológicamente la expliquen. De ahí que, teniendo en cuenta, por un lado, la propuesta y, por otro, los personajes implicados en ella, puede llegarse a la conclusión de que la estructura en ambas obras consta fundamentalmente de tres partes: 1) los personajes antes de la escena central; 2) los personajes en la escena central; 3 ) los personajes después de dicha escena ${ }^{8}$.

La escena central se compone de tres momentos: a) Anselmo e Ichirô preparan psicológicamente a los receptores de sus respectivas propuestas; b) formulan la propuesta; c) los receptores se niegan en un primer momento a realizarla, pero finalmente acceden para evitar mayores problemas. Tanto la preparación psicológica como la propuesta y el asentimiento, tienen lugar en plena naturaleza, a solas, sin testigos. En Cervantes es un prado «fuera de la ciudad»; en Sôseki, dos templos budistas solitarios. Con una ligera diferencia: en Cervantes a la preparación sigue inmediatamente la propuesta. En Sôseki ambas están separadas por un breve espacio de tiempo, casi un día, en que los dos hermanos han de volver al hotel donde también se hospedan Nao y la madre. Diferencia obvia, debida a la economía temporal necesaria en toda novela corta.

Los parlamentos de Anselmo e Ichirô revelan el intenso sufrimiento interior que ha desgarrado sus almas, provocando con ello, igual y paralelamente, una especie de agonía y auténtica compasión en sus interlocutores. Anselmo revela a Lotario su infelicidad y desabrimiento, el deseo extraño y fuera del uso común que le fatiga y le angustia «no sé que días a esta parte» $[33,400]$. Y apelando al entrañable vínculo de amistad que les une, confía en que la diligencia de Lotario podrá remediarle, ya que, como añade más tarde, se trata de una «enfermedad», una situación parecida a la

- Se han propuesto otras estructuras para El curioso. Por ejemplo, Georges GONTRRT ( El curioso impertinente, novela clave del Quijote», en Cervantes: su obra y su mundo. M. Criado de Val, dir. Madrid, Edi-6, 1981, pp. 783-788), propone una estructura de tres partes basada en el cambio que el 'ser' y el 'parecer' de Camila experimentan a lo lango de la narración. 
muerte, o, en otras palabras, un antojo absurdo como el de algunas mujeres que les da por comer carbón o yeso.

Ichirô revela a su hermano, desde el primer momento, la obsesión que le angustia. "¿Está Nao enamorada de ti??" [II, 18] Jirô queda estupefacto ante la pregunta, pues Nao es la mujer de su propio hermano. Ichirô no se conforma con esa respuesta «artificial»; y, dolorosamente, le confiesa cuánta humillación le ha supuesto decidirse a pisotear su propia dignidad para hacer voz su secreta angustia. E insiste: "Quiero conocer tus verdaderos sentimientos» [II, 18]. Vuelve a responderle Jirô con las mismas palabras. Y entonces a Ichirô se le llenan los ojos de lágrimas, dice estar avergonzado de haberle hecho una pregunta tan infantil y estúpida y le pide perdón por dudar de su palabra. Con todo, pregunta una vez más, primero en términos generales y enseguida más concretamente, sobre la incógnita que le atormenta: "¿Puede alguien leer la mente de otra persona (...) de la persona más cercana a ti, de la que debería serte más entrañable?» [II, 20] Jirô le dice que es imposible conocer completamente el corazón ajeno, por ser las personas individuos autónomos. Sólo la religión, es decir, la fe podría superar ese obstáculo. Pero Ichirô, intelectual rodeado siempre de libros ${ }^{9}$, admite que sólo puede «pensar, pensar, pensar»...; y, acto seguido, suplica en tonos patéticos a su hermano: "Jirô, por favor, ayúdame a creer» [II, 21].

La comparación de estos momentos previos a la escena axial en ambas novelas arroja una sutil diferencia. La actitud de Ichirô es de súplica, de ruego, mientras que la de Anselmo encierra más bien semas de exigencia, como si por el vínculo de amistad que le une con Lotario tuviera derecho a su complicidad y asentimiento. Además, el sufnimiento de Ichirô, frente a la determinación seca y sin atenuantes de Anselmo, está descrito con trazos de un mayor desvalimiento: lágrimas, vergüenza, rostro hundido en el pecho, vacilación, tristeza.

La causa de que Anselmo e Ichirô hayan elegido respectivamente a Lotario y a Jirô como cómplices para la realización de sus obsesiones es más compleja de lo que a primera vista parece. Tanto que pudiera pensarse que lo que les impulsa no es sólo probar

9 El carácter de intelectual y profesor que Sôseki ha dado a su personaje revela una 'versión' o interpretación del personaje cervantino de Anselmo no totalmente nueva. Ya lo hizo el autor (probablemente Lope de Vega) de La necedad del discreto en la figura de Laureano, aunque la actitud soberbia y autosuficiente de éste dista mucho de la desorientación de que es víctima Ichirô. Véase Jarme Fernandez S. J., «El individual ismo como causa de deshonra: La necedad del discreto de Lope de Vegax, ponencia leída en el X Congreso de la AIH (Barcelona, Agosto, 1989), de próxima aparición en las Actas del mismo. 
el honor de sus esposas, sino también la fidelidad del amigo y del hermano. Después de su boda con Camila, Anselmo se ha sentido más y más solo por las repetidas ausencias de Lotario, llegando incluso a decirle «que si él supiera que el casarse había de ser parte para no comunicalle como solía, que jamás lo hubiera hecho» [33, 398]. Ante tal afimación apasionada, que para más de un cervantista entrana una clara connotación de homosexualidad (opinión, a mi parecer, bastante gratuita y, además, totalmente innecesaria para la comprensión de la novela) ${ }^{10}$, Lotario promete cambiar de actitud, pero en realidad no lo hace, pues «procuraba dezmar, frisar y acortar los días del concierto del ir a su casa» (...) «y los ocupaba y entretenía en otras cosas, que él daba a entender ser inexcusables» $[33,399]$. Esta frialdad de Lotario va a ser un factor decisivo para que en la mente de Anselmo cobre mayores tonos de necesidad y urgencia la realización de su extraño deseo. Y, junto a la frialdad del amigo, una sutil sospecha respecto a su esposa. Que Camila sea un dechado de perfecciones constituye una premisa que admiten abiertamente los dos amigos. Mas no debe olvidarse que Anselmo, «era algo más inclinado a los pasatiempos amorosos» [33, 397]; es decir, había frecuentado el trato con muchas mujeres y -puede fácilmente inferirse- habia comprobado por sí mismo hasta cierto punto la verdad de todos esos tópicos aplicados a la mujer, que luego aparecen en el sermón de su amigo, de que es frágil como el «vidrio» y delicada como el «armino», o que es «animal imperfectox. Esta subconsciente sospecha de la firmeza de toda mujer y la frialdad de Lotario, cuya amistad era para él un tesoro inapreciable y en parte irremediablemente perdido, son los factores que le hacen concebir el extraño deseo. Anselmo quiere asegurarse de que Lotario sigue siéndole fiel y de que siempre estará limpia de sospechas la firmeza de Camila.

También la extraña decisión de Ichinó de pedir al hermano que ponga a prueba la integridad de Nao, su esposa, obedece, en interesante paralelismo, a una frialdad y a una sospecha. Frialdad no del amigo, sino de la esposa; y sospecha no de la esposa, sino respecto al hermano. Sôseki puso el conflicto en el seno de la familia,

10 En Japón es partidario de la relación homosexual de los dos amigos florentinos - y también de los dos hermanos japoneses - el psiquiatra Dr. TAKBo DoI. En su libro The Psychological World of Natsume Soseki, citado antes (p. 95) fue quien primero apuntó en un breve párrafo la posible influencia cervantina en Hombre en camino. En este punto reside el valor de su referencia, y no en la afirmación tajante de khomosexualidad». El Dr. Doi habla leido el Quijote muy por encima, como puede comprobarse líneas antes por la muerte que le atribuye a Anselmo: «and Anselmo, his friendship betrayed, killed himself in a fit of indignation*. 
y prefirió invertir los términos, dando así a su relato una ambigüedad sin solución, mantenida implacablemente hasta el mismo final. Ichirô sufre porque ha querido entender a su esposa y ser aceptado por ella, mas todo en vano. Sôseli lo habia apuntado ya. Cuando capítulos antes, Ichirô y Nao pasean a orillas del canal, la madre revela a Jirô su preocupación: «parecen dos seres totalmente extraños que accidentalmente caminasen en la misma dirección» [II, 13]. Nao es una existencia pasiva, de sonrisa siempre lejana, ausente y triste. Así, al menos, la describe el narrador, que no es otro que Jirô. Para Ichirô, Nao es un enigma, un enigma que rezuma frialdad e indiferencia. En la mente de Ichirô ha crecido la sospecha de que la raíz de tal frialdad está en su hermano. Y aunque asegura varias veces: «Jirô, confío en ti, pero sospecho de Nao» [II, 25], la verdad es muy otra. Porque de Nao, más que sospecha, lo que tiene en realidad es una dolorosa certidumbre, la de su indiferencia y crueldad. La verdadera sospecha es respecto al hermano. Una sospecha que le irá creciendo dentro en tal manera que, cuando estalle en palabras la víspera de la marcha de Jirô, ya no dejará lugar a ambigüedad alguna: Jirô y Nao son para él como Paolo y Francesca. Como el de estos amantes, su amor adúltero adquirirá con el paso del tiempo tintes románticos, hasta que el mundo acabe por olvidar injustamente su burda inmoralidad y el nombre del esposo burlado [II, 27].

La formulación de la propuesta de seducción guarda también una notable semejanza. No obstante el preámbulo de preparación psicológica, las propuestas de Anselmo e Ichirô resultan para sus receptores inesperadas y fulminantes: En El curioso, Anselmo decide: «Deseo que Camila mi esposa (...) se acrisole y quilate en el fuego de verse requerida y solicitada», para ordenarle luego al amigo: «quiero, joh amigo Lotario!, que te dispongas a ser el instrumento que labre aquesta obra de mi gustow [33, 401]. En Hombre en camino, una y otra vez previene Ichirô a su hermano de que no se sorprenda por el favor que va a pedirle, y le dice: «Quiero que pongas a prueba el honor de Naow [II, 24].

Es preciso detenerse brevemente para analizar la naturaleza de estas propuestas, de contenido idéntico, aunque distintas en la expresión. Anselmo piensa que Camila es buena y perfecta, pero duda de su propia opinión sobre ella: «el deseo que me fatiga es pensar si Camila, mi esposa, es tan buena y tan perfecta como yo pienson $[33,400]$. Anselmo quiere probar el temple de Camila, conocer los quilates de su bondad; en otras palabras, quiere asegurarse y saber con certeza si esa bondad es verdadera y cualidad genuina de su «esencia». Nótese, además, que ese «como yo pienso» significa «como yo creo». Pero se trata de un creer que nada tiene que ver 
con la fe. Anselmo se manifiesta así como un ser tremendamente débil e inseguro, porque se ha situado en las arenas movedizas de lo puramente subjetivo. Y en consecuencia ni la fe ni la razón cuentan en su mundo. No la fe verdadera, pues sólo «creerán si el experimento que va a realizar con su esposa produce un resultado favorable. Ni tampoco la razón, porque, según él mismo admite, sólo obedece a su «gusto». Y es ese «gusto» el que, contra toda razón y justicia, le lleva a forjar toda una serie de "razones» que justifiquen en su mente enferma la absurda decisión.

Por su parte, Ichirô afirma que Nao le es fría, huidiza y cruel. No se trata de frialdad sexual. Haciendo suyas unas palabras del poeta inglés finisecular George Meredith, dice que envidia a los hombres que sólo se contentan con la belleza externa de la mujer o con el placer de la carne [II, 20]. Y añade que a él lo único que podría satisfacerle sería apresar el alma, el espíritu de la mujer o, como indicará en otra ocasión, su «esencia» (hontai). Indudablemente Ichirô no es feliz. Insatisfacción de Ichirô, desabrimiento de Anselmo. Sentimientos intolerables que sólo podrán calmarse con el conocimiento total y la posesión absoluta de la persona amada. En el fondo el deseo de Ichirô apunta a algo tan imposible como el de Anselmo. Tras estas actitudes radicales se oculta un claro rechazo de la naturaleza humana como es en realidad y un desafío al misterio que somos.

Sôseki ha tratado de razonar en su novela lo que, genialmente, Cervantes había querido ex professo poner en El curioso como totalmente irrazonable. El deseo de Anselmo - una inimaginable «costosa experiencia» [35, 445], como al final sentenciará el cura-constituye un acto gratuito como el de Don Quijote en Sierra Morena, aunque infinitamente más peligroso, pues Don Quijote no juega a experimentar con seres humanos ${ }^{11}$. El de Ichirô no es acto gratuito. Entraña crueldad, es un acto monstruoso éticamente hablando, pero «inteligible» y xjustificable» si se contempla a la luz de la ley del talión, ya que es también una venganza contra la crueldad de $\mathrm{NaO}^{12}$.

1 Para una excelente exposición de este tema, véase Juan B. Avalle-ARce, «La vida como obra de arte», en Don Quijote como forma de vida. Madrid, Fundación Juan March/Editorial Castalia, 1976, pp. 144-172. Véase también JoAQutN CASALDURRO, aLectura de una novela modernax, en Sentido y forma del "Quijote". Madrid, Insula, 1975, 4." ed., p. 158.

12 RBNe GIRARD (Mentira romántica y verdad novelesca. Traduc. de Joaquín Jondá. Madrid, Editorial Anagrama, 1985) y CesAreo Bandera (Mimesis conflictiva. Ficción literaria y violencia en Cervantes y Calderon. Madrid, Gredos, 1975), entre los críticos occidentales, y Yoshinori Nishinaga (art. cit.), en Japón, explicarian esto, sin embargo, con la metafísica del deseo, su naturaleza mimética, el mediador, la rivalidad, etc. La teoría me parece sólidamente fundada e interesante. Pero, en mi 
Es interesante observar que la resonancia de la propuesta tiene asimismo extraordinaria semejanza en ambas novelas. Lotario y Jirô se han negado rotundamente en un primer momento, aterrados ante un proyecto absurdo y carente de toda ética, invocando además la propia deshonra que ello les acarrearía. Pero también más tarde y en curioso paralelismo aceptan ser cómplices: 1) para evitar mayores problemas; 2) porque Anselmo e Ichirô les han insinuado que tampoco se trata de llegar en la seducción a extremos burdos y vulgares; y 3) porque tanto Lotario como Jirô piensan que Anselmo e Ichirô han perdido el juicio. Jirô lo anota lacónicamente: «En medio del mutuo acaloramiento hubo un momento en que me pregunté si no tendría perturbadas sus facultades mentales» [II, 25]. Lotario lo expresa de otro modo distinto, por medio de un largo y detallado parlamento en que, con todos los tonos y matices posibles, le da a entender a Anselmo que su proyecto es absurdo y propio de un demente. Que Anselmo no escuche ninguna de aquellas poderosas razones, indica cuán alienado está del mundo de la más elemental cordura.

En ambas novelas el asedio a la esposa debe comenzar sin dilación: «desde otro día siguiente» [33, 410], anota el narrador de $E l$ curioso; «hazlo mañana mismo» [II, 25], dice Ichirô en Hombre en camino. El lugar del asedio es distinto: Lotario deberá rendir a Camila en su misma casa. Jirô irá con Nao al cercano pueblo de Wakayama. La actitud de los impertinentes esposos es también distinta: Anselmo se aleja de ellos; Ichirô hace que se alejen. En un primer momento, nada sucede ni en la novela de Cervantes ni en la japonesa. $Y$, sin embargo, a partir de este momento ambas narraciones experimentan una divergencia apreciable. En realidad los asedios de Lotario no van a tener lugar. Durante días y páginas serán fingidos. La tensión toma colores de absurdo -insistencia terca de Anselmo, asentimientos falsos de Lotario-, a lo largo de una serie de escenas que se repiten con ligeras variantes. Vence por fin la terquedad del esposo, y la actitud de Lotario pierde el tono de simulación ante la belleza de Camila cada vez más sentida: «porque si la lengua callaba, el pensamiento discurría y tenía lugar de contemplar, parte por parte, todos los estremos de bondad y de hermosura que Camila tenía, bastantes a enamorar una estatua de mármol, no que un corazón de carne» $[33,415]$. Y, aunque la conciencia moral deja oir su voz y se entabla en el alma de Lotario un

opinión, no explica, sino sólo en parte, El curioso y Hombre en camino. Es un 'sub-tema' de ambas novelas. Sólo en este sentido me parece valida. Si se aplica con pretensiones de totalidad tiene el peligro de ser, como indica RUTH EL SAFFAR, un prefabricated game of metaphysical desire («Beyond Conflict», Cervantes, 1, 1 y 2, 1981, p. 88. 
doloroso conflicto, acaba por triunfar la pasión transformándose en insistencia incansable donde el fingimiento ya no es posible. Tanto que antes que caiga por tierra la fidelidad de la esposa ejemplar — Rindióse Camila; Camila se rindió» $[34,418]$ - caerá la del «virtuoso y prudentex amigo.

En Hombre en camino nunca tendrá lugar de forma manifiesta la traición y el deshonor de la esposa. A diferencia de Cervantes, Sôseki no quiso presentar a sus personajes como los seres «modélicos» y «ejemplares» que eran Camila y Lotario, sino dotarlos de sentimientos equívocos de mutua atracción e instintivo rechazo, lejanías y acercamientos, en un inquietante movimiento de lanzadera afectiva. Para ello, quiso expresamente detenerse en la descripción de esas horas que, por orden de Ichirô, han de pasar su hermano y Nao en Wakayama, y prolongarlas mediante una tormenta para forzar a la pareja a compartir también a solas toda una noche ${ }^{13}$.

Comienza el episodio con una situación embarazosa: silencio de Jiró y extrañeza de Nao durante el breve viaje a Wakayama. Llegan a una casa de té. Cielo encapotado que amenaza lluvia. Jirô no sabe cómo abordar el tema. Empieza a llover. Preocupación de Jirô por el regreso a Wakanoura y porque psicológicamente se siente incapaz de hablar con Nao sobre el tema. Nao, sin embargo, está dispuesta a regresar. Jirô siente que Nao se está divirtiendo con la apurada situación ${ }^{14}$. Cuando por fin Jirô consigue hablarle de su hermano, Nao se muestra en un primer momento indiferente y fría. Jirô se lo echa en cara y entonces Nao contesta apasionadamente que hace cuanto puede por él, que pone toda su alma en atenderle y servirle, aunque a veces, - confiesa - se siente como un cuerpo sin alma, inconsciente de lo que le rodea. Nao estalla en sollozos. Admite que Ichirô, aunque difícil de tratar, es íntegro y sincero. $Y$ añade con un ambiguo interrogante: «¿Piensas que podría querer a otro hombre?» [II, 32].

Los sentimientos que Nao ha despertado en Jirô podrian resumirse en un saberse desarmado y atraído por ella, como «las limaduras de hierro ante un poderoso imán», en un haber acusado muy

13 La descripción del encuentro, pintura magistral en que los trazos de la conciencia y el subconsciente aparecen inextricablemente entrelazados, ocupa desde el cap. 28 al 39 de la II Parte.

14 Muy probablemente Nao se ha dado cuenta del sentido último que tiene ese improvisado y extraño viaje con Jiro. En este punto hay una sutil semejanza con Camila. Tampoco Camila nunca conoció la naturaleza de la descabellada propuesta que su esposo hiciera a Lotario. Pero quizá llegó a sospechar de las intenciones de aquel, por sus repetidas e infundadas ausencias. Para este punto, vease RUTH El SAPPAR, Beyond Fiction. The Recovery of the Feminine in the Novels of Cervantes. Berkeley, University of California Press, 1984, pp. 72-74. 
hondo esas lágrimas que él mismo hubiera querido enjugar y en una genuina admiración por su ternura y sufrimiento. (Sentimientos gemelos de los de Lotario ante la contemplación de la bondad y hermosura de Camila). Puede que tales rasgos parezcan anodinos a más de un lector. Pero su carga semántica es muy intensa, si se tiene en cuenta que es Jirô quien los anota. El lector ha de creerle. Pudo haberlos silenciado. Pudo haberles dado otros tonos de mayor pasión que quizás tuvieron. Si no lo ha hecho es sencillamente por cierta timidez o porque, al tratarse de la propia intimidad, toda revelación es imperfecta y tal vez imposible. No obstante, su narración parece fidedigna cuando anota:

\begin{abstract}
«Estuve a punto de decirle que no me importara que fuese menos amable conmigo con tal de que lo fuese algo más con mi hermano. Pero miré sus ojos y entonces, una vez más, cá en la cuenta de mi estúpida debilidad sentimental. Pensé incluso que, ahora que estaba frente a ella, era ya incapaz de hacer algo genuino y sincero por mi hermano. No me faltaban las palabras $y$ de haber querido pude haber hablado sin problemas en favor suyo. "De haber querido...", porque ahora, dijera lo que dijese, todo resultaria en abogar por mi propia causa y no por la de mi hermano. En realidad, me sentía indigno de esá misión que se me habia confiado, y ahora más que nunca me pesaba en el alma» [II, 31].
\end{abstract}

Jirô siente vergüenza de haber pensado así. Vergüenza, porque el abandonarse a ese sentimiento de amor significa haber traicionado ya en cierto sentido a su hermano. Conciencia moral que deja ó́r su voz con tonos parecidos a los que sintió Lotario cuando se dio cuenta que había empezado a desear a Camila.

Una doncella de la casa de té les anuncia que en Wakanoura ha estallado una fuerte tormenta. El regreso inmediato es imposible. Se trasladan entonces a un hotel cercano para pasar la noche. Jiró trata en vano de comunicarse por teléfono con el hotel de Wakanoura. La lluvia arrecia, el viento es cada vez más huracanado. Un corte de luz eléctrica deja todo sumido en una oscuridad total. Nao y Jirô son presa del terror. Ni siquiera a hablar se atreven. A la luz de una vela que trae una doncella del hotel consiguen tomar un baño y se preparan para acostarse. Jirô nota que Nao se ha maquillado. Arrecia la tormenta de truenos y relámpagos. Incapaz de conciliar el sueño habla con Nao. También ella está preocupada por Ichirô y por la madre. Pero no tiene miedo a la tormenta. Y añade que le gustaría contemplar como un inmenso maremoto lo destruía todo, que le gustaria morir herida por un rayo o arrastrada por las aguas en una inundación... Además, ha hecho esta confesión con calma, con mayor serenidad y dominio que pudiera tener cualquier hombre. «La mayoría de los hombres - concluye, quizás con doble 
sentido- son cobardes en los momentos difíciles» [II, 37]. Nao ha venido pensando en esta muerte sublime día tras día.

Una vez más, Jiró anota las sensaciones que esta noche violenta ha dejado en su alma. Ha sentido un íntimo gozo de saberse a solas con Nao, gozo que en algún momento se transformó en terror al pensar en su familia. Ha experimentado una indecible sensación de intimidad con su cuñada y una embriagadora sensación de placer. Notas personales que ante el lector desvelan, en ráfagas de inconfundible sentido, el interior del personaje.

A la mañana siguiente, brilla el sol en un cielo inmensamente azul. La azarosa aventura y la tormenta han pasado. Jirô advierte en Nao un cambio radical. Nada del apasionado romanticismo de la noche anterior. En sus facciones sólo se reflejan la palidez y la modestia de siempre. Nao es un laberinto, un misterio indescifrable -apunta Jino - y siente compasión por su hermano, en cuyo lugar, piensa con espanto, nunca quisiera encontrarse. Nótese que si el cambio de Nao ha sido sorprendente, no menos lo es el de Jirô. Jirô, el narrador, con estas breves palabras escamotea o pretende ignorar el dato importante de su amor por Nao. Y concluye precipitadamente que carece de todo sentido darle un informe detallado a Ichirô, pues todos los datos que él pudiera revelarle le llevarían a la única conclusión, ya conocida por él, de que Nao es un misterio.

Aquí hay varios elementos que Sôseki va a desarrollar con magistral ambigüedad a lo largo de su narración: Amor subconsciente (o secreto) de Jiró por Nao ${ }^{15}$; Nao como «misterio y laberinto». Jirô se limita a decirle a su hermano (al día siguiente, poco antes de regresar a Tokyo) sólo una parte de lo que sabe sobre ella: que no puede abrigar duda alguna sobre su integridad y fidelidad conyugal. Pero nunca le dará una relación concreta de lo que esa noche pudo averiguar. que Nao hace todo lo que puede por él, que pone toda el alma en atenderle, que no puede querer a otro hombre; ni tampoco le dirá sus palabras apasionadas sobre el valor para afrontar la muerte más violenta o su contínuo pensar en el suicidio; ni le revelará que su aparente frialdad o indiferencia sólo se debe a

15 Este amor secreto, nunca reconocido abiertamente, entre Nao y Jiro, ha sido puesto de relieve por un gran sector de la critica japonesa de Sóseki. Tanto que algunos -n mi opinión, no muy acertadamente - han pretendido darle el valor de tema central de Hombre en camino. AsI, Toshrmko ITO, «Kojin-ron no zentei» [Premisas para el estudio de 'Hombre en camino']. Nihon Bungaku [Literatura japonesa], marzo, 1969. Para una critica de tal punto de vista, vease YASUo SHIGEMATSU, "Kojin ni okeru 'Jir6 no ai'. Itó setsu no kento wo tooshite» [El amor de Jiro en 'Hombre en camino'. Reflexiones sobre la teoria de Ito]. Kaishaku to kansho [Interpretación y apreciacion], septiembre, 1970. 
que se siente necia o inútil. Eso nunca lo dirá. Y eso es lo que Ichirô habría querido desesperadamente oír de labios de su hermano. Puede que tal revelación no hubiera cambiado en absoluto la situación, pero Ichirô en el fondo sólo deseaba saber que alguien sintonizaba con él y le ayudaba a soportar su falta de fe en la vida y en los seres humanos. En este punto consiste la traición de Jirô a su hermano. Una traición que se prolonga hasta el mismo final de la novela. Siempre irá aplazando Jirô el momento de informar a su hermano, tanto que a veces se siente tranquilo al pensar que lo ha olvidado. Ichirô, no obstante, espera paciente que sea el mismo Jirô quien venga a darle un informe más detallado. Algo tuvo que pasar aquella noche, algo tuvo que observar Jirô en Nao durante tantas horas... Pero Jirô nunca irá más allá de aquella escueta información. Jirô es aquí como Lotario, antes y después de haber seducido a Camila. Con la única excepción del largo discurso en que trató de convencer al amigo de la irrazonable y demencial actitud que había tomado, nunca dirá Lotario a Anselmo la verdad. Anselmo no sospecha de su amigo. Ichirô sí sospecha de su hermano.

Jirô vela esa actitud pérfida que, por ser él el narrador, nunca quedará apuntada expresamente en la novela, con la preocupación que una y otra vez dice sentir por la salud mental de su hermano, llegando incluso a buscarle como última solución ese viaje con « $\mathrm{H}$, colega y amigo de Ichirô, para que le observe e informe con todo detalle de su estado mental ${ }^{16}$. ¿Es, en realidad, verdadera preocupación? ¿O es más bien un contrapunto irónico, una sutil venganza al informe que sobre Nao le había pedido Ichirô a él? ¿Es de verdad Jirô, por su carácter despreocupado y un tanto alegre, incapaz de comprender el doloroso conflicto mental de su hermano? Quizás obedezca la ambigüedad de Jirô al amor que siente por Nao, o a una secreta esperanza de poder poseerla algún día, factor que, por otra parte, puede que sea decisivo en su rechazo de toda oportunidad de casarse. ¿O tal vez lo que le retrae del matrimonio es la tragedia insoluble que ve en la vida conyugal de su hermano?

16 La carta o informe de «H» ocupa los últimos 25 capítulos de la novela [IV, 28-52]. Nótese que aquí el narrador no es Jirô. El informe, cuyo análisis dejo de lado por obvias razones de espacio en este trabajo, expone detalladamente la angustia mental de Ichiró. Es la angustia del hombre japonés de fines del XIX, atrapado en la violenta transición del Japón feudal de la Epoca Tokugawa al Japón moderno de la Epoca Meiji. El Prof. Yu («Introducción» a su traducción inglesa de la novela, ya citada, p. 21) escribe: «Thanks to the latter (letter) device Kojin becomes something more significant, more profound than a mere domestic tragedy». Y compara el conflicto socio-cultural del hombre japonés de Meiji al del europeo del Renacimiento, atrying to escape the shadow of the Medieval world», para acabar apuntando la proximidad espiritual que Ichiró tiene con Hamlet. Aguda observación que puede igualmente aplicarse, y con toda justicia, al Anselmo cervantino. 
Por su parte, Nao está descrita con una actitud ambigua. No sólo en la noche pasada a solas con Jirô, sino también en la visita que hace a su apartamento privado (la escena del brasero en que sentada frente a Jirô acerca seductora el rostro hasta casi rozar el suyo) [IV, 2-4], se muestra al lector como una persona inteligente, decidida y tremendamente activa, tan en divergencia con la pasividad, tristeza y lejanía que suele adoptar en su vida familiar de cada día. Si a Jirô lo trata a veces en un tono de intimidad impropio de una mujer casada, es en otras ocasiones distante y seca. Nao es un enigma no sólo para Ichirô y para su hermano. También lo es para la madre. «¿Es Nao buena o mala?», pregunta a Jirô, poco antes de que éste abandone la casa para vivir aparte [III, 38]. Y lo será hasta la última línea de la novela. Esta ambivalencia de Nao ofrece puntos paralelos a la que el lector comienza a adivinar en la Camila de después de la caída, cuando, con la exquisita representación de la defensa de su honor, llega a desconcertar incluso al mismo Lotario ${ }^{17}$. Sea como fuere, la ambigüedad de Sôseki es algo esencial en la cultura japonesa, que algún autor ha venido a definir como «cultura del difuminado», donde los perfiles lingüísticos, artísticos, literanios aparecen intencionalmente borrosos y envueltos en una como neblina estética ${ }^{18}$. Pero, al mismo tiempo, es una ambigüedad que debe mucho a Cervantes.

En ambas novelas es central el tema del conocimiento de la verdad. Se arranca del deseo de conocer algo. El objeto no es otro que un ser humano, una persona. Anselmo cree conocer a Camila y piensa que es perfecta, pero duda de su propio juicio y quiere saber si «esencialmente» lo es. Ichirô cree conocer a Nao, y piensa que es fría y cruel, pero quiere saber el último por qué de esa actitud, su «espíritu», su «esencia». Anselmo e Ichirô piensan, imaginan, usan su razón subjetivamente para aportar «razones». Tal postura sería válida respecto a cosas u objetos. Pero bajo ningún concepto lo es cuando el término del conocimiento es una persona. La razón sólo puede captar lo cortical, la superficie del hombre. El

17 En Camila hay un cambio radical, de mujer virtuosa en «la mujer taimada de la tradición folklórica», como agudamente expone MATME CHEVALIRR, «Lorenza, Leonora, Camila, en Teorlas semiologicas aplicadas a textos españoles, Actas del I Symposium Intern. del Dep. de Español de la Univ. de Groningen. José L. AlonsoHernández, ed. Universidad de Groningen (Holanda), 1980, p. 32. Chevalier finaliza su artículo señalando la ambiguedad que Cervantes infundió a su novela: «Al recordar la tradición folklórica de la casada engañosa y al plasmar el personaje de Camila adúltera sobre un tipo que a cada paso le ofrecían los cuentos viejos, Cervantes dio al «Curioso un aspecto solapado de tragicomedia e hizo de un relato que podía ser ejemplar una novela ambiguax.

18 TAKRHKKO KeNMOCHI, «Nijimi» no Nihon Bunka [La cultura japonesa del difuminado]. Tokyo, PHP Kenkyajo, 1984. 
ser humano es un misterio. Lo es Camila y lo es Nao. Sôseki ha tenido cuidado en apuntarlo directamente una y otra vez: enigma, laberinto, misterio. Cervantes lo ha repetido de forma más indirecta y general decenas de veces, empedrando su relato con múltiples términos de la esfera conceptual de la verdad: «verdad», «artificio», «verdadero», «falso», «mentira», «cierto», «engaño», «embuste», «fingimiento»... Así es. El ser humano es un misterio, y la única vía de acceso a él es el amor, un amor que en última instancia está hecho de fe, y de fe se alimenta. Un poeta español lo ha dicho bellamente en un endecasílabo: "No puedo definirte sino amándote» ${ }^{19}$. Anselmo e Ichirô no aman a sus esposas, por la sencilla razón de que no creen en ellas ${ }^{20}$. Es más, en realidad, no saben qué es creer. Piensan que la fe se reduce a una suma de pruebas empíricas, y por ello cosifican a sus esposas usándolas como objetos de laboratorio, como realidades estáticas ${ }^{21}$. Parecen inferir que la superación de la prueba hará innecesarios ulteriores experimentos. No comprenden que el ser humano es un dinamismo siempre cambiante, siempre en camino, proyecto necesitado de un constante hacerse y sujeto sin treguas a las más imprevistas alteraciones, «siempre en peligro de venirse todo abajo, pues, en fin, se sustenta sobre los débiles arrimos de su flaca naturaleza» $[33,414]$. Anselmo e Ichirô niegan a sus esposas lo que de personal, libre y autónomo, lo que de absoluta otredad poseen ${ }^{22}$. Ambos serían incapaces de comprender la verdad que encierra el apotegma moral de Machado: «Enseña el Cristo: a tu prójimo / amarás como a ti mismo, / más nunca olvides que es otro. / Dijo otra verdad: / busca el tú que nunca es tuyo, / ni puede serlo jamás» ${ }^{23}$. Puede que en el fondo Anselmo e Ichirô hayan presentido la imposibilidad de poseer absolutamente a sus esposas, pero se rebelan para lograr lo imposible, como Prometeo

19 LeOPOldo Panero, «Cándida puerta (1960)». En Poesía (1932-1960). Madrid, Ediciones de Cultura Hispánica, 1963.

20 Difiero en este punto de KENNETH BROWN ( El curioso impertinente, una homilia novelesca, en Cervantes: su obra y su mundo. M. Criado de Val, dir. Madrid, Edi-6, 1981, p. 795), pues, 1) no se trata directamente de fe teológica (aunque no quede descartada, ya que Anselmo no cree en Dios), sino más bien de fe antropológica, fe en el ser humano; y 2) más que 'falta de fe en el amor' (conyugal), el problema de Anselmo es, a mi parecer, falta de verdadero amor derivada de una falta de fe en el otro.

21 Vease Edward C. RIRY, Don Quixote. London, Allen \& Unwin, 1986, p. 82.

22 En este punto me siento más cerca de Ruth El Saffar que de Cesáreo Bandera («On Beyond Conflict»... Cervantes, 1, 1 y 2, 1981, 83-110, aunque puntualizando que la aabsoluta otredad sa entiendo válida en cuanto referida a todo ser humano.

23 ANTonio Machudo, «Nuevas canciones (1917-1930)», CLXI («Proverbios y cantares», 42 y 43), en Poesias completas, I. Oreste Macri, ed. Madrid, Espasa Calpe, 1989, p. 634. 
lo hiciera para arrebatar el fuego sagrado de los dioses. Y dejando de lado la fe, el amor y la razón, se crean un universo artificial que les facilite la realización de su experimento ${ }^{24}$. Las consecuencias y resultados de tal actitud son una paralela falta de amor y de fe en las personas que les eran más cercanas y entrañables. De todo ello va a desprenderse una triste verdad que quedará flotando tras la lectura de ambas obras, la inmensa dificultad del hombre para la auténtica comunicación humana, y que les va a conducir a ambos a un fin trágico: muerte en El curioso, locura en Hombre en camino.

Tal dificultad de comunicación arranca, a mi parecer, de un hondo sentimiento de soledad. La soledad enfermiza, soledad sin raíces, de Ichirô muestra una innegable semejanza con la de Anselmo. Que un hombre casado con la mujer que ha querido, con una mujer «perfecta» en todos los sentidos posibles, se encuentre desabrido porque cree que le falta el amigo, y si lo atrae de nuevo a su intimidad es sólo para que seduzca a su propia esposa, significa que ese hombre, Anselmo, padece de una soledad inmensa y alienante. El mismo Anselmo busca una solución desesperada para destruir esa soledad en la construcción de un universo que sólo puede ser imagen de su mismo vacío interior, un hermético e inhabitable infierno, donde el amor es imposible, y del que sólo se puede salir, tras concienciar su oquedad y reconocer su viciada factura, con la muerte. También Ichirô ha creado su propio mundo. Incapaz de aceptar al ser humano como el misterio que es, se ha ido aislando entre sus libros, imposibilitándose para relacionarse con todos: con sus padres, con su esposa, con su hijita, con sus hermanos. La petición a Jiró de que ponga a prueba el honor de Nao indica claramente esa imposibilidad trágica y significa al mismo tiempo una llamada angustiosa de auxilio para salir de ese mundo por él mismo creado y que ahora le resulta prisión intolerable. Pero los seres humanos, aun los más cercanos y entrañables, no podrán o no sabrán ayudarle, sino que, muy por el contrario, le sumirán en una vorágine de sospechas y recelos. Igual que en el caso de Anselmo, ya que Lotario y Camila, lejos de socorrerle, acabaron por tender en torno a él una invisible pero espesa red de hirientes engaños, simulaciones y mentiras.

El universo de Ichirô, dolorosamente concienciado, no acaba con la última página de la novela. El final de Hombre en camino, a diferencia del que quiso Cervantes para El curioso, es un final sin solución ni salida. La ambigüedad de las relaciones de Jirô y Nao,

24 Ver Juan B. Avalle-Arce, aEl curioso y El capitan (Cervantes y la verdad artística)», en Nuevos deslindes cervantinos. Barcelona, Ariel, 1975, pp. 139-140. 
la ambivalencia de la actitud de ésta con su esposo, la sospecha de Ichirô respecto a la autenticidad (makoto) última de su mujer y su hermano, la falta de comprensión entre los tres lados de este triángulo humano, todo ello continúa implacablemente. A diferencia de la solución final de El curioso, en la novela japonesa nada se soluciona. Jirô no se casa, Nao sigue con su aire de indiferencia y su sonrisa triste. Ichirô, incapaz de creer como al principio, se va hundiendo inevitablemente en una más intensa locura. No hay conciencia de pecado ni lugar para el perdón. Sólo una espesa niebla moral en la que es preciso seguir viviendo. El absurdo infierno, del que pudo salir Anselmo, merced al reconocimiento de su error y al perdón de su esposa, y del que después pudieron salir, sólo en cierto sentido, Lotario y Camila (Lotario "tande arrepentido» y Camila, profesa entre tristezas y melancolías) merced a la muerte, ese infierno atenaza todavía en sus entrañas a Ichirô, a Nao y a Jirô... Sôseki ha sabido situar en las coordenadas espirituales de su tiempo y exasperar magistralmente, sin exorbitar los trazos, la tragedia humana de Cervantes ${ }^{25}$.

JAIME Fernandez S. J. Sophia University, Tokyo

25 He llegado a esta conclusión respecto a $E l$ curioso, gracias a la comparación con Hombre en camino. El final de El curioso es innegablemente trágico -trágico, porque han quedado rotas absurdamente unas relaciones humanas y destrozadas unas vidas que nunca debieron malograrse- pero no en el sentido de condenación eterna al infierno, como indica KENNETH Brown (art. cit., pp. 796797). Puede que la muerte de Anselmo sea «al margen de la religión» (al no haber sacerdote y confesión), como apunta Avalle-ArCe ( $E l$ curioso y El capitán», cit., p. 139). Pero de esto no se puede concluir la condenación eterna. Al menos, Cervantes no lo dice en parte alguna, ni tampoco puede arrogarse la autoridad de arrojar a nadie por toda la eternidad al infierno. Por el contrario, dice que Anselmo murio reconociendo su error y perdonando, califica a Lotario de «arrepentido amigo» y de Camila apunta su profesión religiosa y su muerte entre tristezas y melancolías. Son, a mi parecer, gestos de piedad de Cervantes para con sus personajes, un rayo de esperanza, por más tenue que sea, en medio de la oscuridad final. 


\section{APÉNDICE}

\section{NATSUME SOSEKI: Hombre en camino (Resumen)}

La familia Nagano vive en Banchô, barrio de Tokyo. El Sr. Nagano es un oficial del gobierno, ya retirado. Él y su esposa Otsuna han confiado la administración de su casa a Ichirô, su hijo mayor. Ichirô es profesor de universidad, está casado con Nao y tienen una hija, Yoshie. En la misma casa viven Jirố y Oshige, dos hermanos solteros de Ichirô.

Ichirô es un prestigioso investigador, aunque, como persona, difícil y sensible. No suele abandonar su despacho, en el segundo piso de la casa, y durante la cena se suele mostrar taciturno e irritable. Mientras la madre trata de seguirle la coniente al hijo y el padre de suavizar los problemas, la familia confia que Nao encuentre un medio de calmar los nervios de Ichiró. Pero Nao o no quiere o no puede hacerlo.

Al comienzo de la novela, el hermano menor, Jirô, se encuentra en Osaka, enviado por la familia para concertar el matrimonio de Osada, una de las sirvientas de la casa. Jiró no tiene mucha idea de lo que es concertar un buen matrimonio. Su preocupación es un amigo suyo, llamado Misawa, que acaba de llegar a Osaka y ha tenido que ser hospitalizado con úlceras. Jiró se esfuerza por cuidar a Misawa, pero pronto se inita porque Misawa difiere su salida del hospital para seguir al lado de una geisha que agoniza en la habitación contigua.

Misawa sale del hospital. Ichirô, acompañado de su madre y su esposa Nao, llega a Osaka. Es un viaje de placer, aunque a la vez vienen a ver cómo es el marido que Jirô ha buscado para Osada. Cuando acaban las gestiones, la familia va a pasar unos días a Wakanoura, lugar al lado del mar en la Península de Ise.

Ichirô sigue tan irritable como de costumbre. Le dice confidencialmente a Jiró que la causa de su infelicidad es la indiferencia de Nao. Se lamenta de que no sabe cuáles son en realidad los verdaderos sentimientos de su mujer. Sospechando que Nao está en el fondo enamorada de Jiró, le propone a éste someterla a una prueba. Llevará a Nao a un lugar cer- 
cano y pasará la noche con ella. Jirô rechaza la descabellada propuesta, pero finalmente se ve forzado a aceptarla cuando su hermano invoca el principio de la lealtad fraterna.

A la manana siguiente Jirô y Nao salen para almorzar juntos en Wakayama. El cielo amenaza tormenta. Sus relaciones han sido siempre distendidas, pero, mientras Nao parece estar contenta con este inusitado momento lejos de la familia, Jirô siente una extraña desazón. En la casa de té saca el tema de las relaciones de Nao con su esposo. Nao insiste en que ha hecho todo lo que ha podido. Jirô siente pena por Nao. Entonces comienza una fuerte tormenta y no pueden volver a Wakanoura. Jirô se siente a disgusto por tener que pasar con su cuñada la noche en un hotel.

La tormenta cobra intensidad. Se corta la corriente eléctrica. Traen velas a la habitación. Nao disfruta de la aventura. Si tuviera que morir, dice, preferiría que fuese a manos de un maremoto o un rayo. "Pero la mayoría de los hombres» - añade antes de retirarse a descansar - $\alpha$ son cobardes en situaciones diff́ciles». Jiró no puede conciliar el sueño y fuma incansable. A la mañana siguiente, ya de vuelta en Wakanoura, informa a su hermano de que no puede dudar de la integridad de Nao. Cuando vuelvan a Tokyo le dará un informe más detallado de las horas que pasó con Nao.

Algunas semanas después, el Sr. Nagano atiende a varios invitados en su casa y presume de su habilidad para solucionar asuntos ajenos. Dice que le pidieron visitar a una mujer, que habia sido seducida y abandonada 20 años antes. La mujer estaba ahora ciega, y el seductor quería darle algún dinero. Aunque la mujer había rechazado el regalo, quería desesperadamente saber por qué aquel hombre la abandonó. El Sr. Nagano le aseguro que, de haber sido entonces otras las circunstancias, aquel hombre se habría casado con ella.

A todos los concurrentes les parece muy bien la historia, menos a Ichirô, que luego en su despacho acorrala a Jirô y cita el caso como una prueba de la falta de sinceridad de su padre. Y le dice que también él, Jirô, posee el mismo rasgo negativo. Así como el padre ha ocultado la verdad a aquella ciega, Jiró todavía no le ha dicho la verdad sobre lo que pasó aquella noche en Wakayama. Los hermanos discuten, y Jirô decide marcharse de la casa. Ichiró acepta con calma esta decisión de su hermano. Y, después de leerle en voz alta el pasaje de Dante que narra los amores ilícitos de Francesca da Rimini y su cuñado Paolo, expresa su convicción de que Jiró le ha traicionado.

Jiró comienza a trabajar para la empresa de Mr. B. Evita ir a su casa de Banchó durante todo el invierno, pero le llegan noticias de la extraña conducta de su hermano en la universidad. Una noche de primavera, Nao aparece de pronto en su apartamento. Jiró sospecha que Ichiró se ha comportado violentamente con ella. Finalmente, a ruego de sus padres va a su casa. Oshige le dice que Ichirb le ha obligado participar en unas pruebas de «telepatía», que él mismo está realizando.

La familia decide pedir a H., el mejor amigo de Ichirô, que salga con él de viaje. Jiró le ruega a $\mathrm{H}$. que anote sus impresiones sobre la conduc- 
ta de Ichirô. Tales impresiones están anotadas en una carta que ocupa los últimos capítulos de la novela.

Según la carta, los dos han viajado por la Península de Izu y se encuentran ahora en Benigayatsu, en una casa de campo que un amigo les ha cedido. Es aquí donde Ichirô, después de 10 días de desazón, ha conseguido dormir por primera vez. $H$. se da cuenta de que Ichirô tiene una seria perturbación mental. Cree $H$. que la causa del sufrimiento de Ichirô estriba en que su elevada sensibilidad (estética, ética e intelectual) le hace incapaz de tener una actitud más pedestre respecto a la vida. Siente que sólo la religión le puede ofrecer una esperanza, una alternativa que Ichirô rechaza categóricamente. Incapaz de creer o de suicidarse, el mismo Ichirô sugiere que su única salida es la locura.

JAIME FernANDeZ S. J. 